\title{
Inbred or outbred? An evaluation of the functional allogenicity of farm sheep used in cardiac valve studies
}

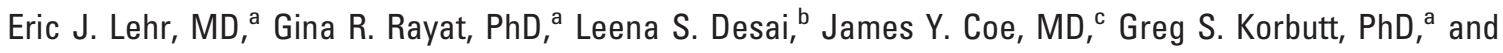
David B. Ross, MD

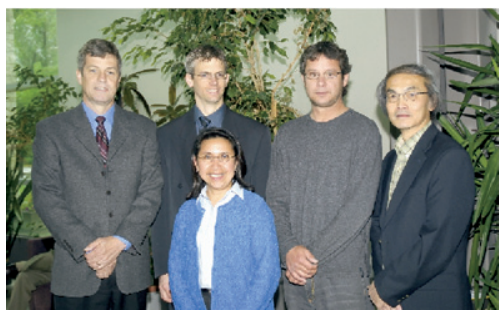

Back row (left to right): Drs Ross, Lehr, Korbutt, and Coe; front row, Dr Rayat.

Objective: Cryopreserved allograft cardiovascular tissue elicits a strong cellular and humoral response in recipients; this may accelerate the deterioration of the allograft and complicate future heart transplantation. Juvenile sheep are the standard model for in vivo valve research and have been used to investigate the allogeneic immune response to cardiac valve and vascular tissue transplantation. Studies to date have not considered the extent of allogenicity of sheep used in transplantation studies.

Methods: Functional allogenicity was assessed by standard one-way mixed lymphocyte reaction assay using peripheral blood mononuclear cells. Responder cells were stimulated with irradiated stimulator cells and cultured at $37^{\circ} \mathrm{C}$ in $95 \%$ air and $5 \%$ carbon dioxide for $3,4,5$, and 6 days. Cultures were pulsed with tritiated thymidine for 24 hours and harvested onto filtermats.

Results: The allogeneic response, measured as counts per minute, demonstrated a bimodal distribution. Fifty-nine $(36.9 \%)$ of 160 pairs fell within the first peak (counts per minute $<10,000$ ) and were defined as weak responders. The remaining $101(63.1 \%)$ of 160 pairs of animals demonstrated a strong allogeneic response (counts per minute $\geq 10,000$ ) that followed a normal distribution.

Conclusions: More than 1 in 3 pairs of sheep is too closely related to elicit an immune response when cross-reacted. This finding may alter the interpretation of studies that base their findings on allogeneic transplantations in sheep without ascertaining the genetic similarities of the animals. Valve transplantation studies in a sheep model should assess the extent of allogenicity of donor and recipient sheep.

From the Department of Surgery, ${ }^{a}$ Faculty of Science, ${ }^{\mathrm{b}}$ and Department of Pediatrics, ${ }^{\mathrm{c}}$ University of Alberta, Edmonton, Alberta, Canada.

Funding for this work was provided by the University Hospital Foundation and the Edmonton Civic Employees' Charitable Assistance Fund.

Dr Lehr is a Canadian Institutes of Health Research Strategic Training Fellow in TORCH (Tomorrow's Research Cardiovascular Health Professionals). Dr Rayat is a Canadian Diabetes Association Scholar, and Dr Korbutt is an Alberta Heritage Foundation for Medical Research Senior Scholar.

Address for reprints: Eric J. Lehr, MD, Department of Surgery, University of Alberta Hospital, Dvorkin Lounge, 8440 112th St, Edmonton, AB, Canada T6G 2B7 (E-mail: elehr@ualberta.ca).

J Thorac Cardiovasc Surg 2006;132:1156-61 $0022-5223 / \$ 32.00$

Copyright (๑) 2006 by The American Association for Thoracic Surgery

doi:10.1016/j.jtcvs.2006.06.026 $\longrightarrow$ ryopreserved allograft cardiovascular tissue elicits a strong cellular and humoral ${ }^{1-3}$ immune response in recipients. When it is used to correct congenital heart defects in children, the host immune response may accelerate the deterioration of the allograft, ${ }^{4}$ resulting in reduced freedom from reoperation, ${ }^{5}$ and may complicate future heart transplantation. ${ }^{6,7}$ Increasing data suggest that decellularizing the allograft may attenuate the host's immune response. ${ }^{8}$

Inbred rodent models have been valuable in characterizing the alloreactive immune response against cryopreserved cardiovascular tissue ${ }^{8,9}$; however, preclinical work requires the use of large-animal models to confirm the immunologic findings in large animals and to assess safety of the valve or tissue. The US Food and Drug Administration highly suggests testing cardiovascular tissue in sheep, ${ }^{10}$ which are comparable in size to humans and provide an accelerated model of calcification. ${ }^{11}$ Accordingly, there are several reports considering the effect of decellularization on the alloresponse. ${ }^{12,13}$ These studies assume allogenicity of the animals but do not assess the degree of inbreeding between donor and recipient animals. Unlike rat and mouse models, sheep used for animal studies are taken from flocks raised for human consumption. Although many farmers attempt to minimize inbreeding, the level of allogenicity within flocks has not been described. Further- 


\section{Abbreviations and Acronyms \\ $\mathrm{CPM}=$ counts per minute \\ MHC = major histocompatibility complex \\ MLR = mixed lymphocyte reaction \\ $\mathrm{PBMC}=$ peripheral blood mononuclear cell}

more, there are no well-characterized flocks of inbred sheep available to ensure allogenicity between donors and recipients. We therefore sought to determine the level of inbreeding within a flock of local farm sheep.

Because the ovine major histocompatibility complex (MHC) is incompletely characterized, we chose to perform a functional assay. The alloresponsiveness of MHC antigens between potential transplant donors and recipients can be assessed by in vitro mixed lymphocyte reaction (MLR) assay. MLR primarily reflects the allogeneic immune response against class II donor-specific antigens. Although genotyping has replaced functional assays for tissue-typing donors and recipients in clinical organ transplantation, MLR has been recently shown to predict patients who are at high risk for graft failure and may be used as an adjunct to DNA methods. ${ }^{14}$ In addition, MLR reactivity may be disparate with results obtained by serologic typing. ${ }^{15}$ MLR remains a viable method of assessing allogenicity. Therefore, we used 1-way MLR assay to study the alloresponsiveness within a group of 19 juvenile sheep.

\section{Materials and Methods \\ Experimental Animals}

Nineteen random sheep were purchased from a local farm and housed in accordance with the guidelines of the Canadian Council of Animal Care ${ }^{16}$ at the University of Alberta farm with food and water ad libitum. Approval for this study was obtained from the Health Sciences Animal Policy and Welfare Committee for the University of Alberta.

\section{Animal Husbandry \\ Suffolk sheep were obtained from a local farm that raises approx- imately 1800 food-quality lambs per year from 1000 ewes and 50 rams. To minimize inbreeding, the rams and ewes are divided into 3 groups. Over 3 years, each group of rams is rotated through each group of ewes. Every year, 5 to 6 rams from each group are replaced with rams obtained from various farms across Alberta. Offspring are never bred with their parents or siblings.}

\section{Cell Collection}

Blood was collected from the jugular vein of each sheep and transported at room temperature. Peripheral blood mononuclear cells (PBMCs) were isolated by mixing equal portions of blood and $0.9 \%$ saline (Baxter, Toronto, Ontario, Canada), overlaying on $15 \mathrm{~mL}$ of Lympholyte Mammal density gradient (Cedarlane, Hornby, Ontario, Canada) and centrifuging for 45 minutes at 2200 $\mathrm{rpm}$ at room temperature. The layer of PBMCs was carefully aspirated, and the contaminating red blood cells were lysed with red blood cell lysis buffer ( $\mathrm{pH}$ 7.3). PBMCs were washed twice in $0.9 \%$ saline, and stimulator PBMCs were frozen at a concentration of $2.5 \times 10^{7} / \mathrm{mL}$ in $10 \%$ dimethyl sulfoxide and fetal bovine serum at $-80^{\circ} \mathrm{C}$ until needed. Responder cells were used immediately upon isolation.

\section{One-way MLR}

Alloresponsiveness between sheep was tested by using 1-way MLR assay as previously described. ${ }^{17}$ Briefly, stimulator cells were thawed in $40 \mathrm{~mL}$ of Hanks balanced salt solution (Invitrogen, Burlington, Ontario, Canada) supplemented with 5\% fetal bovine serum and $1 \mathrm{mg} / \mathrm{L}$ deoxyribonuclease (Roche, Laval, Quebec, Canada) and then incubated at $37^{\circ} \mathrm{C}$ for 40 minutes. PBMCs were suspended in $10 \mathrm{~mL}$ of Hanks balanced salt solution and irradiated with 2500 rads on a cobalt 60 irradiator (MDS Nordion, Vancouver, Canada). After irradiation, cells were washed in Hanks balanced salt solution and suspended in Eagle modified essential medium supplemented with $10 \%$ fetal bovine serum, $1.0 \times 10^{-5}$ $\mathrm{mol} / \mathrm{L} 2$-mercaptoethanol, and 1\% penicillin-streptomycin (Sigma, Oakville, Ontario, Canada). Responder cells were harvested on the day of experimentation, isolated as described previously, and suspended in supplemented Eagle modified essential medium.

Stimulator cells $\left(3.0 \times 10^{5}\right)$ and responder cells $\left(5.0 \times 10^{5}\right)$ were cocultured in 96-well flat-bottom tissue culture-treated plates (Falcon, Franklin Lakes, NJ) in a total volume of $0.2 \mathrm{~mL}$ per well. Positive controls consisted of responder cells treated with $0.1 \mathrm{~g} / \mathrm{L}$ concanavalin A (Sigma), and negative controls consisted of stimulator and responder cells alone, as well as double-irradiated stimulator and responder cultures. Cell cultures were performed in triplicate and incubated at $37^{\circ} \mathrm{C}$ in a humidified atmosphere of $5 \%$ carbon dioxide for $4,5,6$, and 7 days. After culture, plates were pulsed with $1 \mu \mathrm{Ci}$ of $\left[{ }^{3} \mathrm{H}\right]$ thymidine (Amersham Biosciences Corp, Piscataway, NJ) per well and incubated again at $37^{\circ} \mathrm{C}$ for 24 hours.

Radiolabeled cells were harvested with a Tomtec Harvester 96 (Tomtec Inc, Hamden, Conn) onto glass filtermats (Wallac Oy, Turku, Finland), and scintillator sheets (Wallac Oy) were melted onto the filtermats. Responder cell proliferation was measured as counts per minute (CPM) on a scintillation counter (Perkin Elmer, Wellesley, Mass). The greatest daily mean proliferation during the 4 days of culture represents the maximum proliferation of each MLR pair. The day when the highest proliferation was observed was considered the day on which the maximum response occurred.

\section{Statistical Analysis}

Continuous data are expressed as mean \pm SEM. Means of multiple groups were compared by 1-way analysis of variance with Scheffé post hoc analysis to compare individual groups by using SPSS 13.0 (SPSS Inc, Chicago, Ill). The funding organizations assumed no role in data collection, analysis, interpretation, or the right to approve or disapprove publication of the final article.

\section{Results}

To determine the relative alloresponsiveness of animals within the study population, 1-way MLR assay was performed on all but 11 combinations of 19 animals taken in pairs; this allowed for analysis of 160 potential donor and 


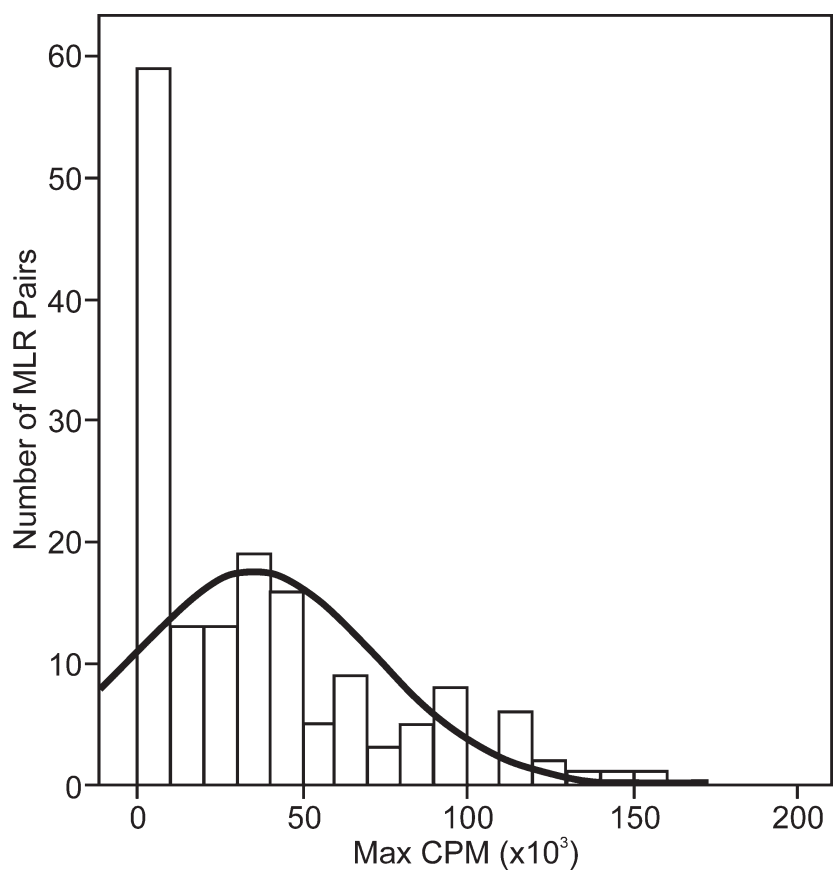

Figure 1. Histogram of the maximum mean proliferation as measured by counts per minute (CPM) for 161 mixed lymphocyte reaction $(M L R)$ pairs performed in triplicate. The overall mean proliferation was $35,019 \pm 2884$ CPM. On the basis of the distribution of the allogeneic response, MLR pairs were categorized into strong (CPM $\geq 10,000)$ and weak (CPM $<10,000)$ groups.

recipient combinations. A wide variation in the proliferation of responder cells after stimulation was observed, with CPM ranging from 63 to $158,169(35,019 \pm 2884)$. Figure 1 demonstrates a histogram of the number of MLR pairs that attained a given proliferative response. A large number of MLR pairs have a proliferative response of less than 10,000 CPM, which represents a weak allogeneic response. The remainder of the group demonstrates a strong response. On the basis of these findings, a negative allogeneic response was defined as CPM of less than 10,000 and a positive response as CPM of 10,000 or greater.

MLR kinetics varied depending on the pair of stimulator and responder cells. The distribution of time to maximum proliferation for negative control and mixed cultures was evenly distributed, with a slight preponderance toward days 6 and 7 (data not shown). Therefore, alloresponsiveness was assessed as the maximum mean proliferation of triplicate experiments from days 4 to 7 . Maximum proliferation in concanavalin A-treated responder cells occurred on day 4 in $81 \%$ of cultures and on day 5 for the remaining groups (data not shown).

Analysis of variance of the proliferative responses of experimental and control groups was performed $(P<.001$; Figure 2). Scheffé post hoc analysis demonstrated that pro-

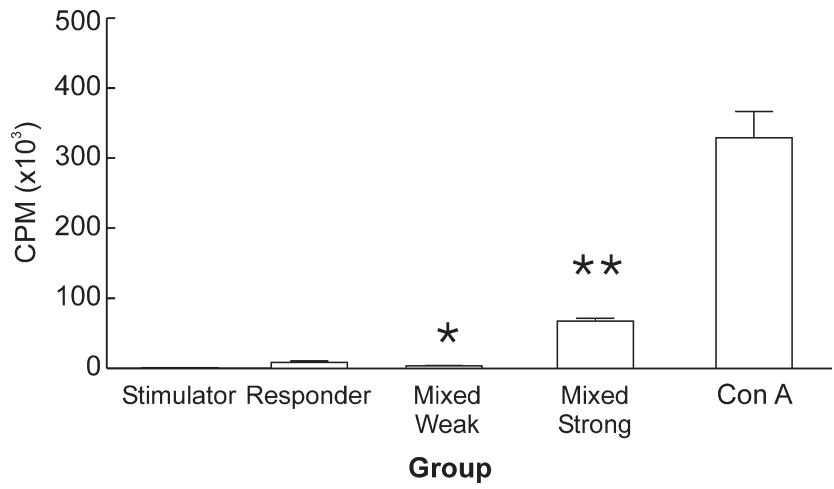

Figure 2. Proliferative response of responder cells. Data are shown as mean counts per minute (CPM) for experimental groups (weak allogeneic response, CPM < 10,000; strong allogeneic response, CPM $\geq 10,000$ ), negative control groups (stimulator cells alone and responder cells alone), and the positive control group (concanavalin A [Con A]-treated responder cells) and compared by analysis of variance. ${ }^{*} \boldsymbol{P} \geq .999$ versus stimulator and responder. ${ }^{* *} \boldsymbol{P}<.01$ versus stimulator, responder, and mixed weak.

liferative responses of the strong responder pairs $(53,934 \pm$ $3351 \mathrm{CPM})$ were significantly greater than the response of either stimulator cells alone (648 $\pm 92 \mathrm{CPM} ; P=.002)$ and responder cells alone $(6731 \pm 1987 \mathrm{CPM} ; P=.011)$. No statistically significant difference in response was identified between the weak allogeneic group $(2640 \pm 305$ CPM $)$ and each negative control group $(P=.999$ for responder cells alone and $P>0.999$ for stimulator cells alone). Concanavalin A-treated responder cells had a significantly higher proliferation than any of the other groups $(263,197 \pm$ 30,252 CPM; $P \leq .001$ for all groups), as expected. Concanavalin A cross-links cell-surface receptors and generates a nonspecific response that is more intense than the allogeneic response. Responder cells treated with concanavalin A are used as a positive control to ensure their viability and proliferative capability.

The MLR results from all 160 combinations tested are summarized in Figure 3. MLRs were categorized as demonstrating either a strong or a weak allogeneic response, as described previously. Fifty-nine (36.9\%) of 160 pairs demonstrated a weak allogeneic response, whereas $101(63.1 \%)$ of 160 pairs demonstrated a strong allogeneic response.

\section{Discussion}

Increasing evidence suggests that allograft heart valves incite a cellular and humoral immune response in the recipient that may sensitize the recipient and play a role in the early failure of these valves. ${ }^{1-4}$ Early studies in allogeneic rodent models have shown that decellularization removes the cellular components of the allograft valve and attenuates this 


\section{Responders}

\begin{tabular}{|c|c|c|c|c|c|c|c|c|c|c|c|c|c|c|c|c|c|c|}
\hline & 2 & 3 & 4 & 5 & 6 & 7 & 8 & 9 & & 11 & 12 & 13 & 14 & 15 & 16 & 17 & 181 & \\
\hline 1 & $S$ & $\bar{S}$ & $\bar{S}$ & $\bar{W}$ & $S$ & $\mathrm{~W}$ & $\mathrm{~S}$ & $S$ & $\mathrm{~s}$ & $\mathrm{~W}$ & $\mathrm{~s}$ & $\mathrm{~S}$ & W & $s$ & $S$ & $\overline{W 1}$ & \begin{tabular}{l|l}
$\mathrm{W}$ \\
\end{tabular} & \\
\hline 2 & & $S$ & $S$ & $\mathrm{~W}$ & $S$ & $\mathrm{~W}$ & $S$ & $S$ & $\mathrm{~W}$ & $\mathrm{~W}$ & $\mathrm{~S}$ & $S$ & W & $S$ & $S$ & $\mathrm{~W}$ & \begin{tabular}{l|l}
$\mathrm{W}$ & $\mathrm{s}$
\end{tabular} & \\
\hline 3 & & & $S$ & $\mathrm{~W}$ & $S$ & $\mathrm{~W}$ & $S$ & $S$ & $\mathrm{~W}$ & W & $\mathrm{S}$ & $S$ & W & $S$ & $\mathrm{~W}$ & $\mathrm{~W}$ & \begin{tabular}{l|l}
$\mathrm{W}$ & $\mathrm{s}$
\end{tabular} & \\
\hline 4 & & & & $\mathrm{~W}$ & $S$ & $\mathrm{~W}$ & $S$ & $S$ & $\mathrm{~W}$ & $\mathrm{~W}$ & $\mathrm{~S}$ & $S$ & W & $\mathrm{S}$ & $\mathrm{S}$ & $\mathrm{W}$ & $\mathrm{W}$ & \\
\hline 5 & & & & & $S$ & $\mathrm{~W}$ & $S$ & $\mathrm{~S}$ & $\mathrm{~W}$ & $\mathrm{~W}$ & $\mathrm{~s}$ & $\mathrm{~S}$ & $S$ & $S$ & $S$ & $\mathrm{~W}$ & \begin{tabular}{l|l}
$S$ \\
\end{tabular} & \\
\hline 6 & & & & & & $\mathrm{~W}$ & $S$ & $S$ & $\mathrm{~S}$ & $\mathrm{~W}$ & $\mathrm{~S}$ & $\mathrm{~S}$ & $\mathrm{~W}$ & $S$ & $\mathrm{~S}$ & $\mathrm{~W}$ & $\bar{W}$ & \\
\hline 7 & & & & & & & $\mathrm{~S}$ & $S$ & $S$ & $\mathrm{~W}$ & W & $S$ & $S$ & $S$ & $\mathrm{~W}$ & $\mathrm{~W}$ & $S$ & \\
\hline 8 & & & & & & & & $\mathrm{~S}$ & $S$ & $\mathrm{~W}$ & W & $\mathrm{N}$ & S & S & W & $\mathrm{W}$ & $S$ & \\
\hline 9 & & & & & & & & & $\mathrm{~S}$ & $\mathrm{~W}$ & W & $\mathrm{N}$ & S & $\mathrm{S}$ & $S$ & $\mathrm{~W}$ & S & \\
\hline 10 & & & & & & & & & & $\mathrm{~N}$ & $\mathrm{~W}$ & $\mathrm{~N}$ & $S$ & $\mathrm{~s}$ & $\mathrm{~W}$ & $\mathrm{~W}$ & $\mathrm{~S}$ & \\
\hline 11 & & & & & & & & & & & $\mathrm{~W}$ & $\mathrm{~N}$ & $\mathrm{~S}$ & $\mathrm{~S}$ & $\mathrm{~W}$ & $\mathrm{~W}$ & $\mathrm{~s}$ & \\
\hline 12 & & & & & & & & & & & & $\mathrm{~N}$ & $S$ & $S$ & $\bar{W}$ & $\mathrm{~W}$ & $S$ & 5 \\
\hline 13 & & & & & & & & & & & & & $\mathrm{~N}$ & $s$ & $S$ & $\mathrm{~S}$ & $\mathrm{~s}$ & 5 \\
\hline 14 & & & & & & & & & & & & & & $\mathrm{~N}$ & $\mathrm{~N}$ & $\mathrm{~N}$ & $\mathrm{~W}$ & $\underline{v}$ \\
\hline 15 & & & & & & & & & & & & & & & $S$ & W & $S$ & 5 \\
\hline 16 & & & & & & & & & & & & & & & & W & $S$ & $S$ \\
\hline 17 & & & & & & & & & & & & & & & & & $S$ & 5 \\
\hline 18 & & & & & & & & & & & & & & & & & & \\
\hline
\end{tabular}

Figure 3. Tabular representation of the distribution of proliferative response measured as counts per minute for 160 mixed lymphocyte reaction pairs. $S$, Strong $(n=101) ; W$, weak $(n=59)$; $N$, not done.

destructive immune process. ${ }^{1}$ Inbred lines of sheep are not readily available as are rodent strains, and most sheep used for laboratory animals are raised on farms for food and may be inbred to some degree. Sheep are a preferred largeanimal model for preclinical testing of vascular tissue and, in particular, heart valves. Studies assessing the effect of decellularization of allograft heart valves on the immune response in large-animal models generally assume that donor and recipient animals are allogeneic, but they do not formally test or report the degree of inbreeding. Laboratorygrade tissue suppliers generally receive animals from slaughterhouses in a single geographic area and cannot provide information regarding the lines of animals from which they receive tissue. Recently, Ketchedjian and associates $^{12}$ conceded that the variability of panel-reactive antibody response in nonprocessed implants that they observed may result from leukocyte antigen similarities arising from inbreeding within supplier flocks of sheep.

Results from our study suggest that more than one third of randomly chosen sheep from a single farm maintaining excellent breeding practices may be too closely related to mount an immune response against recipient tissue. Even within the group of strong responders, a wide variation of proliferative response was observed, and only a few MLR pairs showed a very strong response. This finding may reflect a loss of variability of MHC polymorphisms between animals as a result of inbreeding.

In our study, 5 of 14 animals mounted a strong allogeneic response to all stimulators when the responder cells were exposed to 7 or more stimulator cells (Figure 3). It is unlikely that these responder cells were responding to exogenous factors, because cultures from these animals were prepared on different days. Responder cells may proliferate in response to the serum used in the culture medium. However, only 1 of the 8 homogeneous responders demonstrated a high proliferation when cultured alone. No responder cells demonstrated a uniformly weak allogeneic response. Animals such as these that mount a uniformly strong allogeneic response are the ideal donor animals for allogeneic transplant studies.

Understanding the degree of allogenicity of experimental animals is fundamental to the correct interpretation of results from transplant models based on allogeneic animals when inbred strains are not available. To minimize costs, farm sheep, as with many other large animals, may be bred from a limited number of rams, thereby increasing a flock's inbreeding coefficient. This practice increases the probability of randomly selecting related animals for transplantation. Donor and recipient animals that are considered allogeneic may therefore be syngeneic to some degree; this will reduce the recipient's immune response against the donor tissue. In this situation, a reduced alloimmune response may be falsely attributed to the treatment, when in fact the perceived result is simply a factor of the immunologic similarity between the donor and recipient. When assessing the immune response in large animal transplant models, it is critical to assess the level of allogenicity between donor and recipient animals to correctly interpret the results.

Rotational breeding with partially isolated sire lines effectively reduces inbreeding of commercial female animals and their offspring. Migration between lines may inflate the inbreeding of the females, although maintaining 4 to 5 sire lines may minimize this inflation. ${ }^{18}$ This study clearly demonstrates that even breeding farm sheep with a rotational breeding strategy gives rise to a $37 \%$ probability that 2 allogeneic sheep randomly chosen for transplantation are too closely related to elicit an in vitro immune response. These results further demonstrate the importance of assessing allogenicity before performing transplantation studies.

Several reasons may exist for the inflated level of inbreeding within our flock of sheep. Our supplier of sheep maintains 3 breeding lines of rams, whereas 4 or 5 sire lines are required to minimize inbreeding. ${ }^{18}$ However, by rotating rams off the farm over a 3-year period, our supplier can potentially reduce the coefficient of inbreeding within his flocks of sheep. The effectiveness of this practice to reduce inbreeding, however, is dependent on the genetic dissimilarity of the immigrating rams with the existing flock. Given that sheep are not an endogenous species in Alberta, it is possible that the entire population of sheep in Alberta arose from a limited number of animals and that the flocks in Alberta are relatively closed, thus further increasing the 
inbreeding coefficient. The estimated inbreeding coefficient in some closed herds may be as high as $0.514 .{ }^{19}$

The MHC of vertebrates is a group of cell-surface glycoproteins encoded by a group of closely linked, highly polymorphic genes. This bichain complex binds and presents antigenic peptides to T cells. Whereas the MHC is relatively conserved across mammalian species, ${ }^{20}$ the ovine lymphocyte antigen has yet to be well characterized. Indeed, controversy remains regarding whether 2 or 3 loci encode ovine class I genes. ${ }^{21,22}$ Inbreeding may reduce the number of MHC polymorphisms, thereby increasing the probability that foreign recipient tissue will be seen as self, thus attenuating the allogeneic immune response. ${ }^{23} \mathrm{~A}$ variety of methods for MHC typing have been developed, including serologic testing ${ }^{24}$ and DNA genotyping. Despite the incomplete characterization of the ovine MHC, some authors have been successful at assessing MHC variation in sheep by using DNA genotyping, include polymerase chain reaction/restriction fragment length polymorphism ${ }^{25}$ and sequence-specific primer/polymerase chain reaction. ${ }^{26}$ In vivo and in vitro functional methods are described to assess allogenicity between animals. Split-thickness skin grafts are an excellent in vivo method to assess functional allogenicity, but this method immunologically contaminates the recipient against further studies.

Given the relative importance of the sheep model for cardiovascular immunology research, it may be valuable to develop inbred strains of allogeneic sheep. Such inbred strains would allow further assessment of the immunology of allograft heart valves in a large-animal model. Unfortunately, developing such strains requires a long time commitment, because a minimum of 20 generations of inbreeding would likely be required. It may therefore require more than 20 years of work to develop such strains. ${ }^{19}$ Ideally, several lines of inbred sheep would be available.

In conclusion, we found that more than one third of sheep purchased from a farm using husbandry practices to reduce inbreeding were likely too closely related to elicit a response on an MLR assay. This study demonstrates the importance of determining the degree of allogenicity of sheep in transplantation studies that use allogeneic sheep models. Other methods of measuring allogenicity are available and include serotyping and genotyping. At a minimum, donor and recipient animals should be purchased from separate farms that do not share breeding animals. Wellcharacterized inbred strains of sheep may be ideal for such studies, although reduced ovine leukocyte antigen polymorphisms may make these animals prone to infection, and they may be less representative of the human clinical setting, in which donors and recipients are outbred and have a diverse repertoire of HLA polymorphisms.

The authors thank John Timinski for his assistance with animal handling and Dawne Colwell for assistance in preparation of graphics. We are grateful to Dr Patricia Campbell, director of the University of Alberta Hospital HLA laboratory, for reviewing the manuscript.

\section{References}

1. Meyer SR, Nagendran J, Desai LS, Rayat GR, Churchill TA, Anderson $\mathrm{CC}$, et al. Decellularization reduces the immune response to aortic valve allografts in the rat. $J$ Thorac Cardiovasc Surg. 2005;130: 469-76.

2. Hogan P, Duplock L, Green M, Smith S, Gall KL, Frazer IH, et al. Human aortic valve allografts elicit a donor-specific immune response. J Thorac Cardiovasc Surg. 1996;112:1260-6.

3. Hoekstra F, Witvliet M, Knoop C, Akkersdijk G, Jutte N, Bogers A, et al. Donor-specific anti-human leukocyte antigen class I antibodies after implantation of cardiac valve allografts. J Heart Lung Transplant. 1997; 16:570-2.

4. Dignan R, O'Brien M, Hogan P, Thornton A, Fowler K, Byrne D, et al. Aortic valve allograft structural deterioration is associated with a subset of antibodies to human leukocyte antigens. J Heart Valve Dis. 2003;12:382-90.

5. Yankah AC, Alexi-Meskhishvili V, Weng Y, Schorn K, Lange PE, Hetzer R. Accelerated degeneration of allografts in the first two years of life. Ann Thorac Surg. 1995;60(2 suppl):S71-6.

6. Meyer SR, Campbell PM, Rutledge JM, Halpin AM, Hawkins LE, Lakey JR, et al. Use of an allograft patch in repair of hypoplastic left heart syndrome may complicate future transplantation. Eur J Cardiothorac Surg. 2005;27:554-60.

7. Jacobs JP, Quintessenza JA, Boucek RJ, Morell VO, Botero LM, Badhwar V, et al. Pediatric cardiac transplantation in children with high panel reactive antibody. Ann Thorac Surg. 2004;78:1703-9.

8. Grauss RW, Hazekamp MG, van Vliet S, Gittenberger-de Groot AC, DeRuiter MC. Decellularization of rat aortic valve allografts reduces leaflet destruction and extracellular matrix remodeling. J Thorac Cardiovasc Surg. 2003;126:2003-10.

9. Zhao XM, Green M, Frazer IH, Hogan P, O'Brien MF. Donor-specific immune response after aortic valve allografting in the rat. Ann Thorac Surg. 1994;57:1158-63.

10. U.S. Food and Drug Administration, Division of Cardiovascular, Respiratory, and Neurological Devices, October 14, 1994. Draft Replacement Heart Valve Guidance.

11. Herijgers P, Ozaki S, Verbeken E, Van Lommel A, Racz R, Zietkiewicz M, et al. Calcification characteristics of porcine stentless valves in juvenile sheep. Eur J Cardiothorac Surg. 1999;15:134-42.

12. Ketchedjian A, Kreuger P, Lukoff H, Robinson E, Linthurst-Jones A, Crouch K, et al. Ovine panel reactive antibody assay of HLA responsivity to allograft bioengineered vascular scaffolds. J Thorac Cardiovasc Surg. 2005;129:159-66.

13. Hawkins JA, Hillman ND, Lambert LM, Jones J, Di Russo GB, Profaizer $\mathrm{T}$, et al. Immunogenicity of decellularized cryopreserved allografts in pediatric cardiac surgery: comparison with standard cryopreserved allografts. J Thorac Cardiovasc Surg. 2003;126:247-52.

14. El Agroudy AE, Ismail AM, El Chenawy FA, Shehab El-Din AB, Ghoneim MA. Pretransplant mixed lymphocyte culture still has an impact on graft survival. Am J Nephrol. 2004;24:296-300.

15. Smith RA, Belcher R. Disparity in HLA-DR typing and mixed lymphocyte culture reactivity. Ann Clin Lab Sci. 1987;17:318-23.

16. Olfert FD, Cross BM, McWilliam AA, editors. Guide to the care and use of experimental animals. Vol. 1; 2nd ed. Canadian Council of Animal Care; 1993.

17. Rayat GR, Johnson ZA, Beilke JN, Korbutt GS, Rajotte RV, Gill RG. The degree of phylogenetic disparity of islet grafts dictates the reliance on indirect CD4 T-cell antigen recognition for rejection. Diabetes. 2003;52:1433-40.

18. Honda T, Nomura T, Mukai F. Prediction of inbreeding in commercial females maintained by rotational mating with partially isolated sire lines. J Anim Breed Genet. 2005;122:340-8. 
19. O'Connell PJ, Hawthorne WJ, Simond D, Chapman JR, Chen Y, Patel AT, et al. Genetic and functional evaluation of the level of inbreeding of the Westran pig: a herd with potential for use in xenotransplantation. Xenotransplantation. 2005;12:308-15.

20. Chardon P, Kirszenbaum M, Cullen PR, Geffrotin C, Auffray C, Strominger JL, et al. Analysis of the sheep MHC using HLA class I, II, and C4 cDNA probes. Immunogenetics. 1985;22:349-58.

21. Jugo BM, Joosten I, Grosfeld-Stulemeyer M, Amorena B, Hensen EJ. Immunoprecipitation and isoelectric focusing of sheep MHC class I antigens reveal higher complexity than serology. Eur J Immunogenet. 2002;29:391-9.

22. Grossberger D, Hein W, Marcuz A. Class I major histocompatibility complex cDNA clones from sheep thymus: alternative splicing could make a long cytoplasmic tail. Immunogenetics. 1990;32:77-87.
23. Smulders MJM, Snoek LB, Booy G, Vosman B. Complete loss of MHC genetic diversity in the common hamster (Cricetus cricetus) population in The Netherlands. Consequences for conservation strategies. Conservation Genet. 2003;4:441-51.

24. Lewin HA. Genetic organization, polymorphism and function of the bovine major histocompatibility complex. The major histocompatibility complex of domestic animal species. Boca Raton (FL): CRC Press; 1996.

25. Amills M, Francino O, Sanchez A. A PCR-RFLP typing method for the caprine MHC class II DRB gene. Vet Immunol Immunopathol. 1996;55:255-60.

26. Miltiadou D, Ballingall KT, Ellis SA, Russell GC, McKeever DJ. Haplotype characterization of transcribed ovine major histocompatibility complex (MHC) class I genes. Immunogenetics. 2005;57:499-509. 